\title{
Development and Evaluation of a Standard Method for Screening for Resistance to Radopholus similis in Bananas
}

\author{
Douglas H. Marin, Former Graduate Research Assistant, and Kenneth R. Barker, Professor, North Carolina State \\ University, Raleigh 27695-7616; David T. Kaplan, Nematologist, USDA-ARS, 101 Cove Colony Road, Maitland, \\ FL 32951; and Turner B. Sutton, Professor, and Charles H. Opperman, Associate Professor, North Carolina State \\ University
}

\begin{abstract}
Marin, D. H., Barker, K. R., Kaplan, D. T., Sutton, T. B., and Opperman, C. H. 2000. Development and evaluation of a standard method for screening for resistance to Radopholus similis in bananas. Plant Dis. 84:689-693.

The description and evaluation of a standard assay method for screening for resistance of bananas to the burrowing nematode (Radopholus similis) under greenhouse conditions is presented. Seven banana genotypes, ranging from susceptible to resistant, were used to evaluate the method. Banana plants from tissue culture, grown in 0.4-liter Styrofoam cups containing sterilized sand as substrate, were maintained in the greenhouse for 4 weeks before inoculation. Two hundred burrowing nematodes, reared in monoxenic carrot-disk culture, were used as inoculum for each container. Plants were kept in the greenhouse for an additional 8 weeks at about $27^{\circ} \mathrm{C}$ and $80 \%$ relative humidity after inoculation. Burrowing nematodes reproduced well in the susceptible cultivars False Horn, Grande Naine, Valery, and Lacatan, whereas the reproductive fitness was very low in the resistant cultivars Pisang Jari Buaya and Yangambi. An intermediate reaction between these two groups was observed with Pisang mas. A similar trend was obtained in a follow-up field test, which indicated that the method is accurate and reliable. Assessments of total-root necrosis associated with this pathogen were also comparable between greenhouse and field conditions. However, nematode effects on the roots were more severe in the greenhouse test than in the field. In spite of low nematode reproductive fitness, root necrosis was relatively high in the two resistant cultivars tested in the greenhouse trial.
\end{abstract}

Additional keywords: Cavendish, Musa AAA, nematode resistance

The burrowing nematode, Radopholus similis (Cobb) Thorne, is the most widespread and damaging nematode associated with bananas $(8,28)$. The management of this pathogen is based on the application of granular nematicides combined with agronomic practices (7). Rapid biodegradation of some nematicides, their side effects on nontarget organisms, and contamination of ground and surface water are some of the key reasons why the use of chemical pesticides for nematode control must be modified $(10,23)$. Host resistance is an effective means of nematode control in many crops, but little progress has been made in breeding for resistance in bananas and plantains

Corresponding author: D. H. Marin

E-mail: marin.douglas@freshdelmonte.co.cr

Current address of D. H. Marin: DelMonte Corp., P. O. Box 4084-100, San José; Costa Rica.

This research was supported by the National Banana Corporation, the National Counsel for Scientific and Technological Research of Costa Rica, and the North Carolina Agricultural Research Service.

Accepted for publication 6 March 2000.

Publication no. D-2000-0417-04R

(C) 2000 The American Phytopathological Society because of the genetic complexity within the genus Musa (18).

Early and rapid screening techniques are needed for identifying sources of nematode resistance and in testing breeding materials and resulting hybrids $(1,24)$. A method for screening bananas and plantain cultivars against lesion-forming nematodes has been used in the banana breeding program of the United Fruit Company (now located in Fundación Hondureña de Investigación Agrícola in La Lima, Honduras; 17,19,20). However, a full description of this screening method was not published until 1988 (18). That method involves inoculating plants arising from corms in large containers under semi-controlled conditions in an open greenhouse. It was suggested that plants that have formed a corm better simulate those in field conditions and natural nematode infestations $(17,27)$. However, Sarah et al. (25), using a different approach and nematode reproduction as the key criterion, developed a laboratory technique for screening Musa spp. germplasm. Sarah et al. (26) obtained results similar to preliminary field observations when hardened in vitro plantlets were inoculated with $R$. similis in a growth chamber. The pathogenicity of eight populations of $R$. similis correlated well with reported field performance of nematode populations when evaluated on cv. Poyo (Musa AAA, Cavendish subgroup; 26).

Kaplan (12), working with $R$. similis on a different host (citrus), obtained comparable results to greenhouse experiments when using a glass-culture-tube assay. This system, also based largely on nematode reproduction, required less time, personnel, and space than traditional greenhouse pot experiments. Use of this kind of assay, in conjunction with the relatively short duration of each test, facilitated maintenance of constant conditions and reduced the likelihood of assay contamination.

A standard method for screening bananas for resistance to $R$. similis, which includes nematode reproduction and associated root damage, should include materials and conditions that can be easily repeated in different banana breeding or research programs around the world. Such a method would allow researchers to reach readily comparable conclusions when working under similar conditions. Therefore, the objectives of this research were to evaluate a rapid and early screening method for measuring the resistance to the burrowing nematode under greenhouse conditions, and to compare its accuracy and reliability to conventional field trials.

\section{MATERIALS AND METHODS}

Greenhouse experiment. A monoxenic culture of burrowing nematodes (CR5) reared on carrot disks (16) was established from root samples collected of the La Rita Research Station in Costa Rica. Screening tests were conducted in the greenhouse, using a method adapted from Sarah et al. (24-26), Mateille (15), and Kaplan (12). In addition, associated root damage (root necrosis) was considered. Banana plants from tissue culture were grown in 0.4-liter Styrofoam cups. Seven banana genotypes (Table 1) were selected for this test based on the reported susceptibility or resistance to $R$. similis $(4,21,31)$. A $1: 1$ mixture of sterile coarse river sand and a $254-\mu \mathrm{m}$ silica sand was used as a substrate. A complete nutrient solution (Chem-Gro, HydroGardens Inc., Colorado Springs, CO), based on $100 \mathrm{mg}^{-1 i t e r}{ }^{-1}$ of $\mathrm{N}$, was added twice a week, and deionized water was added as needed. Similar amounts of fertilizer and water were added to all treatments. Before inoculation, plants were acclimated and allowed to grow for 4 
weeks at about $27^{\circ} \mathrm{C}$ and $80 \%$ relative humidity $(\mathrm{RH})$ in the greenhouse.

A mixture of juvenile and adult $R$. similis was extracted from excised carrotdisk culture (13), quantified, concentrated, and resuspended in sterile deionized water (about 40 nematodes $/ \mathrm{ml}$ ). Five $\mathrm{ml}$ of the nematode suspension (about 200 nematodes) was added to the soil at the base of each plant. Inoculated plants were maintained for 8 weeks at about $27^{\circ} \mathrm{C}$ and $80 \%$ $\mathrm{RH}$ in the greenhouse before harvest.

Plant height was measured from the base of the plant to the insertion of the cigar leaf before harvesting the plants. Fresh shoot and root weights also were recorded at harvest. Total root necrosis (0 to 100\%) was visually estimated as a measure of root damage and susceptibility.

Roots were cut in $1-\mathrm{cm}$ pieces and nematodes were extracted by a modified "Mason jar" incubation at $25^{\circ} \mathrm{C}$ for 7 days. Roots were washed on a set of nested sieves and the nematodes were collected on a $38-\mu \mathrm{m}$ pore sieve. Nematodes were resuspended in $100 \mathrm{ml}$ of water, and a 10-ml aliquot was taken. The number of nematodes per $100 \mathrm{~g}$ of roots was estimated from counts under a stereoscopic microscope.

The experiment was conducted and analyzed as a randomized complete block design with 10 replicates and was repeated three times. Two repetitions were conducted in a greenhouse in Raleigh, NC, and a third repetition was performed at La Rita Research Station in Costa Rica. Plantgrowth variables (height, fresh shoot and root weights) and total root necrosis were analyzed individually, using a $t$ test to compare inoculated and noninoculated treatments. Comparisons of plant-growth variables among cultivars were not performed because different genetic groups with different growth habits were used. Nematode data and percent root necrosis were subjected to analyses of variance, and were transformed with $\log _{10}(x+1)$, and square root of $(x)$, respectively, before statistical analyses. Waller-Duncan $k$ ratio $(k=100) t$ tests were computed for these variables. Statistical analyses were performed using SAS (Statistical Analysis Systems, Inc., Cary, NC).

Field experiment. Field plots were established in La Rita Research Station in Costa Rica. Banana plants, belonging to the same genotypes used in the greenhouse trials, were planted under field conditions. Plants in the field were established at a spacing of 3 by $3 \mathrm{~m}$ to minimize interplot interference. Weed control was done manually to avoid herbicide damage to the root system. Fertilization, control of black Sigatoka (caused by Mycosphaerella fijiensis), and all other crop husbandry practices were done as they are commercially practiced in Costa Rica (7).

Banana plants from tissue culture were acclimated and planted in two different plots in he field. Soils of experimental plots belonged to categories $\mathrm{IIs}_{2}$ (poor structure; Typic Hapludand, sandy loam to sandy clay loam) and $\mathrm{Vs}_{1}$ (limited depth; Lytic Hapludand, sandy loam, soil layer $<50 \mathrm{~cm}$ ), according to the banana soil classification system of Jaramillo and Vazquez (11). Before establishment of the experimental plots, banana plants (Musa AAA, cv. Grande Naine) infected with $R$. similis were maintained in the field for 6 months to ensure inoculum availability and avoid disease escapes. Plots were divided into quadrats ( 3 by $6 \mathrm{~m}$ ) and sampled 1 week prior to planting to determine nematode inoculum levels in the field. The $\mathrm{P}_{\mathrm{i}}$ s ranged from 0 to 340,000 nematodes per $100 \mathrm{~g}$ of roots; most quadrats ranged from 20,000 to 40,000 nematodes per $100 \mathrm{~g}$ of roots.

The experiment was designed and analyzed as a randomized complete block design with eight replicates. Each replicate had two experimental units which were sampled alternatively at 12, 16, 20, and 24 weeks after planting. Time of sampling was initially analyzed as a separate source of variation. The field experiment was repeated once. Root weight, root necrosis (0 to $100 \%$ ), and $R$. similis populations were determined as described in greenhouse assays. Root necrosis and nematode data were transformed by the square root of $(x)$ and $\log _{10}(x+1)$, respectively, before statistical analyses. Waller-Duncan $k$ ratio $(k=100) t$ tests were also computed for each variable. Statistical analyses were performed using SAS.

\section{RESULTS}

In the greenhouse tests, there was no significant difference between the plant height of the inoculated and the noninoculated control for any genotype except Pisang Jari Buaya (Fig. 1A). Plants of Pisang Jari Buaya inoculated with $R$. similis were significantly taller than those of

Table 1. Banana genotypes used to evaluate a screening method for resistance to Radopholus similis under greenhouse conditions

\begin{tabular}{llll}
\hline Genotype & Genome & Genetic group & Reaction to $R$. similis \\
\hline False Horn & AAB & Plantain & Susceptible $(3,4,21)$ \\
Grand Naine & AAA & Cavendish & Susceptible $(4,21)$ \\
Valery & AAA & Cavendish & Susceptible $(19,20,21)$ \\
Lacatan & AAA & Cavendish & Susceptible $(21)$ \\
Pisang Jari Buaya (accession III-106) & AA & Pisang Jari Buaya & Resistant $(1,19,20)$ \\
Pisang mas & AA & $\ldots$ & Intermediate $(21)$ \\
Yangambi Km 5 & AAA & Ibota & Resistant $(3,4,9)$ \\
\hline
\end{tabular}

the noninoculated control. Fresh shoot weight of inoculated plants was significantly less than noninoculated controls only for False Horn and Pisang Jari Buaya (Fig. 1B). Shoot weights did not differ between inoculated and noninoculated plants for the other cultivars tested. Root weights of Valery and Yangambi were greater in noninoculated plants than in the inoculated ones (Fig. 1C). Other genotypes did not differ between inoculated and noninoculated treatments.

Percentage of total root necrosis was greater $(P=0.05)$ in inoculated plants than the noninoculated controls for all genotypes tested in greenhouse tests (Fig. 1D). Root necrosis in the noninoculated controls also varied among cultivars, but none of the differences were significant. The Cavendish cultivars (Grande Naine, Valery, and Lacatan) had the highest necrosis values in the noninoculated control, whereas False Horn, Yangambi, and Pisang Jari Buaya showed slightly lower values. The least root necrosis (about 10\%) was exhibited by noninoculated Pisang mas.

The final nematode population per $100 \mathrm{~g}$ of roots $\left(\mathrm{P}_{\mathrm{f}}\right)$ varied among cultivars under greenhouse conditions (Table 2). False Horn (plantain) supported greater reproduction of $R$. similis than the other genotypes tested in the greenhouse. $R$. similis reproduced similarly in all Cavendish cultivars (Valery, Grande Naine, and Lacatan). Although the $\mathrm{P}_{\mathrm{f}}$ of Pisang mas was lower, it did not differ from Grande Naine and Lacatan. The resistant genotypes, Yangambi and Pisang Jari Buaya, had the lowest $\mathrm{P}_{\mathrm{f}}$ of all cultivars.

Nematode populations behaved similarly under field conditions (Table 2). Nematode populations were greatest in the Cavendish cultivars, intermediate in Pisang mas and False Horn, and lowest in Yangambi and Pisang Jari Buaya.

In the greenhouse trials, False Horn, Grande Naine, and Valery exhibited the highest percentage total of root necrosis (Table 3). Lacatan, the other Cavendish cultivar, had less total-root necrosis. Pisang Jari Buaya had an intermediate root necrosis (about 50\%) which was different from all cultivars tested. Pisang mas and Yangambi had less root necrosis than all other cultivars evaluated.

Root necroses for all genotypes were lower in the field experiments (Table 3), but were proportionally similar to those obtained in the greenhouse test. False Horn and the Cavendish cultivars exhibited more root necrosis than Pisang Jari Buaya, Pisang mas, and Yangambi.

\section{DISCUSSION}

The development of the proposed standard method involved adapting and refining systems described previously by Kaplan (12), Pinochet (17), Mateille (15), and Sarah (24,25). An important consideration in our work was to use conditions 
and materials that could be easily provided in any banana breeding or research program.

One of the first tasks was to select a suitable substrate for banana growth and nematode reproduction. Commercial cultivars require well-drained soils with a good balance of nutrients (27). Most factors, including nutrition, need to be adequate to avoid predisposition of plants to infection by $R$. similis. The use of sterile sand in combination with complete nutrients was adequate for plant growth and nematode infection (14). The use of soil was avoided because it might affect the response of the organisms evaluated. Kaplan (12) previously had developed an assay to estimate citrus resistance to the burrowing nematode using citrus seedlings grown in astatula sand, which is the soil type where nematode damage occurs.

The use of 0.4-liter Styrofoam cups allowed plants to grow well; growth was similar to that in $15-\mathrm{cm}$-diameter plastic pots (D. H. Marin, unpublished data). The small cups used little space and similar growth conditions for all plants were easy to maintain. These containers, with no provision for drainage, resulted in some minor but acceptable background root necrosis, especially on secondary roots. Based on other unrelated research, the use of $15-\mathrm{cm}$ clay pots filled with a $1: 1$ soilsand mix minimizes this root necrosis $(\mathrm{K}$. R. Barker, unpublished data).

Maceration and sieving is the most commonly used technique for extracting nematodes in bananas $(2,17)$ and is sometimes used in combination with the centrifugation-flotation method $(5,9)$. However, it is difficult to use where quarantine measures are needed. Kaplan (12) resolved this problem by incubating roots for 7 days to extract burrowing nematodes from citrus roots. When this method was used for extracting $R$. similis from banana roots, it improved precision and provided results similar to those for maceration and sieving although the efficiency was lower (D. H. Marin, unpublished data). Time of incubation can be reduced to 2 days with no effect on results. Approximately $64 \%$ of the nematodes are extracted by the second day of incubation (D. H. Marin, unpublished data).

Plant-growth variables did not differ between inoculated and noninoculated treatments, indicating that these variables
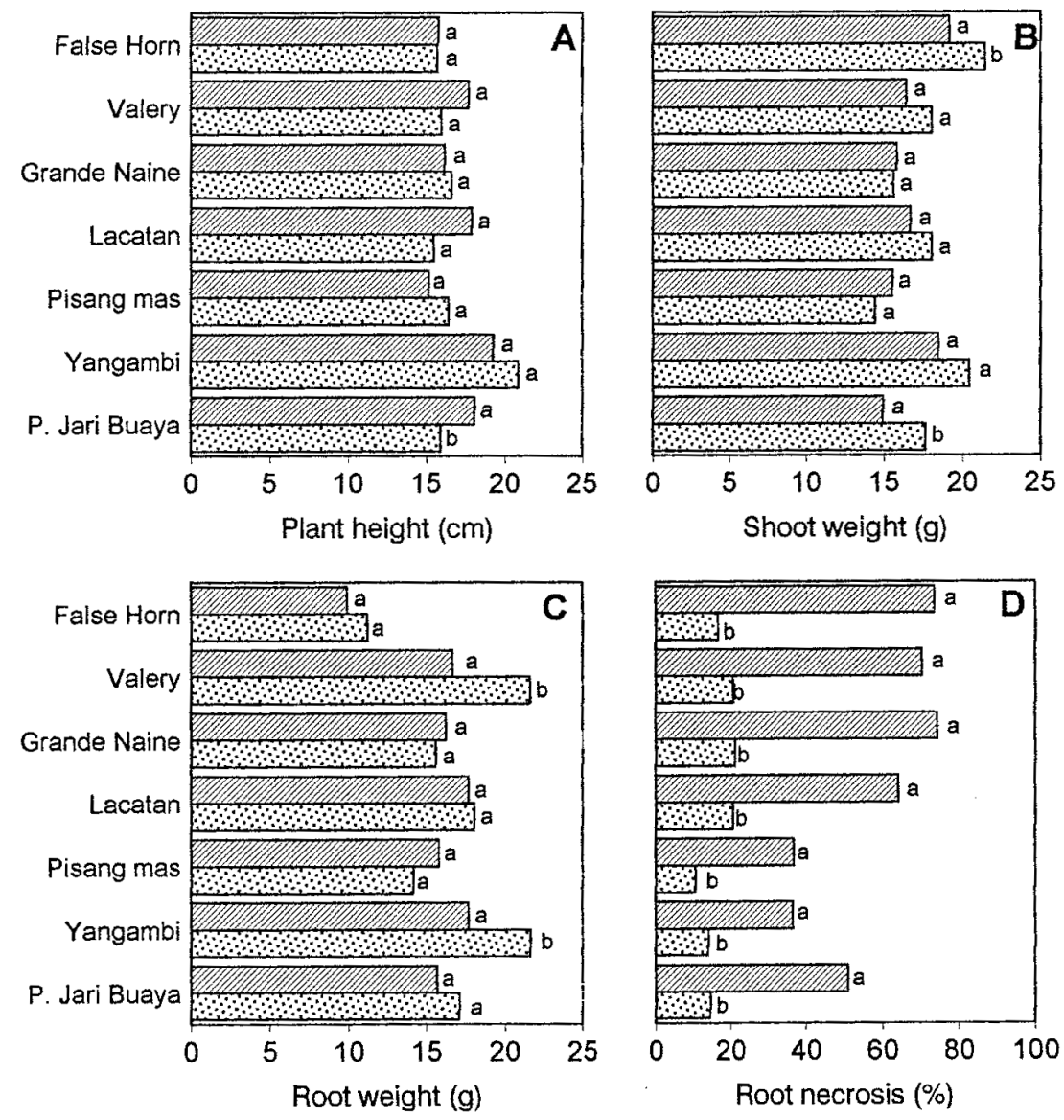

Inoculated Noninoculated

Fig. 1. (A) Plant height, (B) fresh shoot and (C) root weight, and (D) total root necrosis of different banana genotypes inoculated with Radopholus similis under greenhouse conditions. Bars represent means of three replications of the experiments. Bars followed with same letter are not different according to a $t$ test $(P<0.05)$. Pairwise comparisons were performed for each banana genotype.

are not useful for determining nematode damage effects using this screening method. However, the initial size of the plants used, and the short duration of the experiments, may have influenced the responses observed. Our results are in agreement with those of Fallas et al. (5), Hahn et al. (9), and Marin (14).

Root necrosis was a useful parameter in rating host resistance or susceptibility to the burrowing nematode. Root necrosis in the noninoculated control varied among genotypes in the greenhouse tests. Although differences were not very large (about 5 to 10\%), they should be considered when comparing different genetic materials. The magnitude of this necrosis not associated with $R$. similis infection, however, may vary with different test conditions.

The Cavendish cultivars Grande Naine, Valery, and Lacatan and the plantain False Horn were highly susceptible to $R$. similis under greenhouse and field conditions. Although the $\mathrm{P}_{\mathrm{f}} \mathrm{s}$ in the greenhouse were greater than in the field experiment, the rankings were the same. High susceptibility of Cavendish cultivars is well documented (29). False Horn (AAB) was more susceptible than bananas (AAA) under greenhouse conditions. However, nematode populations extracted from plantain

Table 2. Numbers of Radopholus similis extracted from roots of seven banana genotypes under greenhouse and field conditions

\begin{tabular}{lcc}
\hline & \multicolumn{2}{c}{ Nematodes/100g of root $^{\mathbf{Z}}$} \\
\cline { 2 - 3 } Genotype & Greenhouse & Field \\
\hline False Horn & $41,930 \mathrm{a}$ & $20,385 \mathrm{~b}$ \\
Valery & $21,950 \mathrm{~b}$ & $26,154 \mathrm{a}$ \\
Grand Naine & $17,740 \mathrm{bc}$ & $25,385 \mathrm{a}$ \\
Lacatan & $16,775 \mathrm{bc}$ & $22,696 \mathrm{a}$ \\
Pisang mas & $12,580 \mathrm{c}$ & $15,385 \mathrm{~b}$ \\
Yangambi & $2,258 \mathrm{~d}$ & $385 \mathrm{c}$ \\
Pisang Jari Buaya & $1,935 \mathrm{~d}$ & $192 \mathrm{c}$ \\
\hline
\end{tabular}

${ }^{\mathrm{z}}$ Means of three replications of the greenhouse experiment and two replications of the field experiment. Means in a column followed by the same letter are not different according to the Waller-Duncan $k$ ratio $(k=100) t$ test.

Table 3. Total root necrosis (0 to $100 \%$ ) of banana roots infected with Radopholus similis under greenhouse and field conditions

\begin{tabular}{lcc}
\hline & \multicolumn{2}{c}{ Total necrosis $(\%)^{\mathbf{z}}$} \\
\cline { 2 - 3 } Genotype & Greenhouse & Field \\
\hline False Horn & $60.4 \mathrm{a}$ & $25.2 \mathrm{a}$ \\
Grand Naine & $60.2 \mathrm{a}$ & $24.3 \mathrm{a}$ \\
Valery & $60.0 \mathrm{a}$ & $22.6 \mathrm{a}$ \\
Lacatan & $54.8 \mathrm{~b}$ & $22.2 \mathrm{a}$ \\
Pisang Jari Buaya & $45.2 \mathrm{c}$ & $13.9 \mathrm{~b}$ \\
Pisang mas & $32.6 \mathrm{~d}$ & $15.2 \mathrm{~b}$ \\
Yangambi & $31.3 \mathrm{~d}$ & $12.2 \mathrm{~b}$ \\
\hline
\end{tabular}

${ }^{\mathrm{z}}$ Means of three replications of the greenhouse experiment and two replications of the field experiment. Means in a column followed by the same letter are not different according to the Waller-Duncan $k$ ratio $(k=100) t$ test. 
from the field were slightly lower than those obtained from Cavendish cultivars. Price (21), Fogain (6), and Price and McLaren (22) found that Musa AAB are generally more susceptible to $R$. similis than Musa AAA under field and screenhouse conditions. The final nematode population in Pisang mas was intermediate among the genotypes tested, having a $P_{f}$ lower than Cavendish clones and False Horn in both tests. Pisang mas has also shown the same behavior under field and screenhouse conditions $(6,21,22)$.

Yangambi and Pisang Jari Buaya did not differ statistically in the greenhouse and field tests; however, nematode populations were slightly higher for Yangambi. These two cultivars have previously been reported as resistant $(3,4,6,9,19,20,22,30,31)$. Our results demonstrated that Pisang Jari Buaya is highly resistant to $R$. similis but not immune, as previously concluded by Sarah (24).

Root necrosis in the susceptible cultivars in the Cavendish subgroup and in False Horn plantain was relatively high (about $80 \%$ ) in greenhouse tests, which reflected the high nematode $\mathrm{P}_{\mathrm{f}}$ at the conclusion of the greenhouse experiments. Pisang Jari Buaya also showed a high root necrosis (about 50\%), in spite of low $\mathrm{P}_{\mathrm{f}}$. Pisang mas and Yangambi exhibited the lowest root necrosis (about 35\%) under greenhouse conditions. Still, the final population for Yangambi was lower than the one observed in Pisang mas. These differences between root necrosis and $\mathrm{P}_{\mathrm{f}}$ suggest that the experimental conditions might affect expression of nematode populations. Therefore, root necrosis may be misleading if considered separately from reproductive fitness. Our results also indicate that this type of method may not be suitable to evaluate tolerance. Sarah (24) previously suggested that tolerance to nematodes should be determined in field trials.

Susceptibility of False Horn, Grand Naine, Valery, and Lacatan was evident when root necrosis was evaluated under field conditions, whereas the resistant Yangambi and Pisang Jari Buaya showed a similar necrosis to Pisang mas. Root necrosis was lower for all cultivars tested in the field trials, although the general trend was basically the same under both experimental conditions.

Final nematode populations and root necrosis reflected the aggressiveness of the nematode population as well as the susceptibility of the host (14). In spite of the high correlation between $\mathrm{P}_{\mathrm{f}}$ and root necrosis, both variables should be determined. Situations might be encountered in which high $\mathrm{P}_{\mathrm{f}} \mathrm{s}$ are not necessarily associated with severe damage (9).

No differences in root necrosis or $\mathrm{P}_{\mathrm{f}}$ were found among sampling dates in the field trial (data not shown). Nevertheless, the use of repeated sampling minimizes the likelihood of disease escape and improves the accuracy of the determination. Repeated sampling may be a better approach for estimating nematode resistance than to rely on just one evaluation at flowering. When evaluating different genotypes, flowering can occur at different times, and exposure to inoculum would be different. Sampling at the same time would facilitate analyses of differences among banana genotypes.

Previous planting of the experimental plots, especially those with a low infestation, with susceptible infected material helps to standardize the nematode inoculum level and prevent disease escape. Root sampling prior to establishment of resistance determinations can be useful for covariate analyses. In addition, interpolation of nematode data and contour maps are helpful aids to determine potential sites for disease escape (14). A more extensive discussion on techniques used for field screening of germplasm can be found in Price and McLaren (22).

The results obtained with these experiments have demonstrated that our shortterm greenhouse test for evaluating resistance in banana to $R$. similis is reliable and reflects the responses obtained under field conditions. The method, based on nematode reproduction and associated root necrosis, is a rapid and easy way to evaluate advanced breeding lines and select germplasm prior to field trials. It has some advantages over the technique proposed by Sarah et al. (25) because time and space are used more efficiently and the technique employs a substrate that should have a minimum interaction with the organisms evaluated. Additionally, daily variation of temperature and $\mathrm{RH}$ did not affect plant response or relative nematode reproduction in these tests. A growth chamber was not required, which should make the method reproducible in most banana research programs. Furthermore, the nematode extraction procedure is simpler and more precise than conventional procedures, and it is easier to handle under quarantine conditions. This method also can help to narrow the genotypes to be used for field tests. Sarah (24) previously pointed out that these methods are only intended for early elimination of susceptible germplasm, and that final evaluation should be performed under field conditions.

\section{ACKNOWLEDGMENTS}

We thank L. R. Pope, C. S. Echerd, K. M. Parker, A. Barrantes, R. Segura, R. Jimenez, and the Nematode Laboratory personnel of Corporación Bananera Nacional for technical assistance.

\section{LITERATURE CITED}

1. Anonymous. 1988. Recommendations of the nematology workgroup. Pages 15-17 in: Nematodes and the Borer Weevil in Bananas: Present Status of Research and Outlook. Proc. Workshop Bujumbura, Burundi. INIBAP, Montpellier, France.

2. Araya, M., Centeno, M., and Carillo, W. 1995. Densidades poblacionales y frecuencia de los nemátodos parásitos del banano (Musa AAA) en nueve cantones de Costa Rica. CORBANA 20(43):6-11.

3. Binks, R. H., and Gowen, S. R. 1996. Field evaluation of nematode infestations in Musa germplasm at FHIA (La Lima, Honduras). Infomusa 5(2):15-17.

4. Fallas, G., and Marban-Mendoza, N. 1994. Respuesta de tres cultivares y un híbrido de Musa a Radopholus similis en Costa Rica. Nematropica 24:61-164.

5. Fallas, G., Sarah, J. L., and Fargette, M. 1995. Reproductive fitness and pathogenicity of eight Radopholus similis isolates on banana plants (Musa AAA cv. Poyo). Nematropica 25:135-141.

6. Fogain, R. 1996. Screenhouse evaluation of Musa for susceptibility to Radopholus similis: Evaluation of plantains AAB and diploid AA, $\mathrm{AB}$ and $\mathrm{BB}$. Pages 79-86 in: New Frontiers in Resistance Breeding for Nematode, Fusarium and Sigatoka. E. A. Frison, J. P. Horry, and D. De Waele, eds. INIBAP, Montpellier, France.

7. Gowen, S. R. 1995. Pests. Pages 382-402 in: Bananas and Plantains. S. R. Gowen, ed. Chapman \& Hall, London.

8. Gowen, S. R., and Quénéhervé, P. 1990. Nematode parasites of bananas, plantains and abaca. Pages 431-460 in: Plant-Parasitic Nematodes in Subtropical and Tropical Agriculture. M. Luc, R. A. Sikora, and J. Bridge, eds. CAB International, Wallingford, UK.

9. Hahn, M. L., Sarah, J. L., Boisseau, M. Vines, N. J., Wright, D. J., and Burrows, P. R. 1996. Reproductive fitness and pathogenicity of selected Radopholus populations on two cultivars. Plant Pathol. 45:223-231.

10. Jaramillo, R. 1988. Comments on nematological research on Musa spp. in Latin America and the Caribbean. Pages 41-46 in: Nematodes and the Borer Weevil in Bananas: Present Status of Research and Outlook. Proc. Workshop Bujumbura, Burundi. INIBAP, Montpellier, France.

11. Jaramillo, R., and Vázquez, A. 1990. Manual de procedimientos para presentación y realización de estudios detallados de suelos y clasificación de tierras para el cultivo del banano. Edición Revisada. ASBANA, Departamento de Investigaciones Agrícolas. San José, Costa Rica. Mimeografeado.

12. Kaplan, D. T. 1994. An assay to estimate citrus rootstock resistance to burrowing nematodes. Proc. Fla. State Hortic. Soc. 107:85-89.

13. Kaplan, D. T., and Davis, E. L. 1990. Improved nematode extraction from carrot disk culture. J. Nematol. 22:399-406.

14. Marin, D. H. 1997. Characterization and diversity of Radopholus similis populations on selective germplasm of bananas. Ph.D. dissertation. North Carolina State University. Raleigh.

15. Mateille, T. 1994. Comparative host tissue reactions of Musa acuminata (AAA group) cvs. Poyo and Gros Michel roots to three banana-parasitic nematodes. Ann. Appl. Biol. 214:65-73.

16. O'Bannon, J. H., and Taylor, A. L. 1968. Migratory endoparasitic nematodes reared on carrot disks. Phytopathology 58:385.

17. Pinochet, J. 1988. A method for screening bananas and plantains to lesion forming nematodes. Pages 62-65 in: Nematodes and the Borer Weevil in Bananas: Present Status of Research and Outlook. Proc. Workshop Bujumbura, Burundi. INIBAP, Montpellier, France.

18. Pinochet, J. 1988. Comments on the difficulty in breeding bananas and plantains for resistance to nematodes. Rev. Nematol. 11:3-5.

19. Pinochet, J., and Rowe, P. 1978. Reaction of two banana cultivars to three different nema- 
todes. Plant Dis. Rep. 62:727-729.

20. Pinochet, J., and Rowe, P. 1979. Progress in breeding for resistance to Radopholus similis on bananas. Nematropica 9:76-78.

21. Price, N. S. 1994. Field trial evaluation of nematode susceptibility within Musa. Fundam. Appl. Nematol. 17:391-396.

22. Price, N. S., and McLaren, C. G. 1996. Techniques for field screening of Musa germplasm. Pages 87-107 in: New Frontiers in Resistance Breeding for Nematode, Fusarium and Sigatoka. E. A. Frison, J. P. Horry, and D. De Waele, eds. INIBAP, Montpellier, France.

23. Quénéhervé, P. 1993. Nematode management in intensive banana agrosystems: comments and outlook from the Côte d'Ivoire experience. Crop Prot. 12:164-172.
24. Sarah, J. L. 1996. A laboratory method for early varietal screening of banana for resistance to nematodes. Pages 58-61 in: New Frontiers in Resistance Breeding for Nematode, Fusarium and Sigatoka. E. A. Frison, J. P. Horry, and D. De Waele, eds. INIBAP, Montpellier, France.

25. Sarah, J. L., Boisseau, M., Blavignac, F., and Sabatini, C. 1993. Laboratory technique for screening Musa germplasm for nematode resistance. Pages 380-381 in: Breeding Banana and Plantain for Resistance to Diseases and Pests. J. Ganry, ed. CIRAD/INIBAP, Montpellier, France.

26. Sarah, J. L., Sabatini, C., and Boisseau, M. 1993. Differences in pathogenicity to banana (Musa sp. cv. Poyo) among isolates of $R a$ dopholus similis from different production ar- eas of the world. Nematropica 23:75-79.

27. Soto, M. 1992. Bananos: Cultivo y comercialización. 2da ed. Litografía e Imprenta Lil, S.A., San José, Costa Rica.

28. Stover, R. H., and Simmonds, N. W. 1987. Pages 338-343 in: Bananas. 3rd ed. Longman Scientific \& Technical, UK.

29. United Fruit Company. 1962. Varietal susceptibility to Radopholus similis. Pages iv. 73 in: Annu. Rep. La Lima, Honduras.

30. Wehunt, E. J., and Hutchinson, D. J. 1965. Reaction of Musa acuminata accessions to Radopholus similis. Pages 69-72 in: Annu. Rep. United Fruit Co., La Lima, Honduras.

31. Wehunt, E. J., Hutchinson, D. J., and Edwards, D. I. 1978. Reaction of banana cultivars to the burrowing nematode (Radopholus similis). J. Nematol. 10:368-370. 